\title{
Improved derivatization protocol for simultaneous determination of alkylphenol ethoxylates and brominated flame retardants followed by gas chromatography-mass spectrometry analyses
}

\author{
TB Chokwe ${ }^{1 *}$, JO Okonkwo ${ }^{2}$, LL Sibali ${ }^{3}$ and EJ Ncube ${ }^{1}$ \\ 'Scientific Services, Rand Water, Vereeniging 1930, South Africa \\ ${ }^{2}$ Department of Environmental, Water and Earth Sciences, Tshwane University of Technology, Pretoria 0001, South Africa \\ ${ }^{3}$ Directorate of Research and Innovation, Tshwane University of Technology, Pretoria 0001, South Africa
}

\begin{abstract}
An improved derivatization protocol for the simultaneous determination of alkylphenol ethoxylates and brominated flame retardants with heptafluorobutyric anhydride under triethylamine amine base was investigated. The derivatization reaction was completed in $30 \mathrm{~min}$ at $50^{\circ} \mathrm{C}$ using hexane as solvent. Under these conditions, it was observed that alkylphenol ethoxylates and tetrabromobisphenol A were derivatized successfully in the presence of hexabromocyclododecane, lower congeners of polybrominated biphenyls and polybrominated diphenyl ethers. The improved protocol was applied to recovery of analytes of interest from simulated water samples after solid phase extraction. The recoveries achieved were above $60 \%$. The limit of detection and limit of quantification ranged from $0.01-0.20 \mu \mathrm{g} / \ell$ and $0.05-0.66 \mu \mathrm{g} / \ell$, respectively.
\end{abstract}

Keywords: Alkylphenol ethoxylates, brominated flame retardants, gas chromatography-mass spectrometry, heptafluorobutyric anhydride derivatization, simultaneous determination

\section{INTRODUCTION}

Alkylphenol ethoxylates (APEs) and brominated flame retardants (BFRs) are anthropogenic compounds which are often referred to as endocrine disrupting compounds (EDCs) because they have been reported to interact with oestrogen receptors (Stehmann and Schröder, 2004). Studies have shown that APE metabolites are more toxic than their parent compounds, are persistent, and accumulate in fatty tissues (Ying et al., 2002; Petrovic et al., 2003; Gatidou et al., 2007; Sibali et al., 2010). Despite their benefits for reducing fire-related injury and property damage, concern about BFRs is growing because of their occurrence and persistence, and they have been detected in the environment, biota and humans (Alaee et al., 2001; Hyötyläinen and Hartonen, 2002; Polder et al., 2008; Vetter et al., 2008; Yu et al., 2008; Odusanya et al., 2009; Segev et al., 2009; Olukunle et al., 2012)

Determination of low volatility polar compounds such as phenolic analytes has been achieved by indirect analysis using derivatization techniques because such compounds show low sensitivity and tailing in gas chromatographic analysis (Ding and Tzing, 1998; Cathum and Sabik, 2001; Hoai et al., 2003; Esperanza et al., 2004; Stehmann and Schröder, 2004; Fiedler et al., 2007; Gatidou et al., 2007; Dirtu et al., 2008). For the group of compounds covered in the present study, acetylation has been chosen because of its quantitative reactions with various hydroxyl compounds at relatively moderate conditions. In our previous report, heptafluorobutyric acid (HFBA) was used as a derivatizing agent for the determination of APE

This paper was originally presented at the 2014 Water Institute of Southern Africa (WISA) Biennial Conference, Mbombela, 25-29 May 2014.

* To whom all correspondence should be addressed.

e-mail: tchokwe@randwater.co.za and BFR analytes in environmental samples (Chokwe et al., 2012). The procedure described in that report used $\mathrm{Na}_{2} \mathrm{CO}_{3}$ with a derivatization time of $2 \mathrm{~h}$. In another study, Dirtu et al. (2008) derivatized bisphenol A (BPA), tetrabromobisphenol A (TBBPA) and triclosan using pentafluoropropionic anhydride (PFPA) aided by triethylamine (TEA) at $70^{\circ} \mathrm{C}$ for $30 \mathrm{~min}$. In another study, nonylphenol (NP) and BPA were derivatized within $30 \mathrm{~min}$ at $60^{\circ} \mathrm{C}$ using trifluoroacetic acid (TFAA) (Stehmann and Schröder, 2004). Derivatization of nonylphenol polyethoxylate (NPEO) with $n$-propanol-acetylchloride at $80^{\circ} \mathrm{C}$ for $1 \mathrm{~h}$ has also been reported (Ding and Tzing, 1998). Cathum and Sabik (2001) described a derivatization procedure for alkylphenol polyethoxylate surfactants (APnEO) using pentafluorobenzoyl bromide (PFB-Br) as a derivatizing agent aided with $\mathrm{K}_{2} \mathrm{CO}_{3}$ by sonication. The derivatization took $2 \mathrm{~h}$ and was conducted in the dark. Gatidou et al. (2007) reported derivatization of NP, NP2EO, BPA and triclosan with bistrimethylsilylfluoroacetamide (BSTFA) at $65^{\circ} \mathrm{C}$ for 20 min while Fiedler et al. (2007) derivatized alkylphenolic chemicals (APs) with the same reagent at room temperature for $2 \mathrm{~h}$. Furthermore, NPnEO was derivatized with BSTFA in the presence of trimethylchlorosilane (TMCS) at $70^{\circ} \mathrm{C}$ for $4 \mathrm{~h}$ (Esperanza et al., 2004). In a separate study, Hoai et al. (2003) reported derivatized NPnEOs and nonylphenoxy carboxylic acids (NPnECs) with bistrimethylsilylacetamide (BSA) at $25^{\circ} \mathrm{C}$ for $1 \mathrm{~h}$.

In the aforementioned derivatization studies, either higher temperatures and shorter derivatization time, or lower temperatures and longer derivatization time, in the presence of different bases, were reported. It is essential that a balance between derivatization temperature and time should be determined since high temperatures and long derivatization times may not favour analytes of interest that are unstable, such as BFRs, where debromination of higher congeners to lower congeners is possible. This study, therefore, reports on 
improved protocol using HFBA enhanced by triethylamine base derivatization using hexane as the solvent and followed by gas chromatography-mass spectrometry (GC-MS) for the simultaneous determination of APE and BFR analysis. The approach developed in the present study is seen to be milder $\left(50^{\circ} \mathrm{C}\right)$, has a shorter derivatization time $(30 \mathrm{~min})$ and saves sample handling since these compounds can be analysed simultaneously.

\section{METHODS}

\section{Chemicals and standards}

The derivatizing agent, HFBA, was of analytical grade, purchased from Sigma-Aldrich South Africa. The solvents methanol, dichloromethane, acetone and hexane used in the study were of GC grade and were used without further purification. The APEs and polybromobiphenyls (PBBs) were purchased from Laboratories Dr Ehrenstorfer-Schäfers, Augsburg. Only the nonylphenol ethoxylates (NPE), nonylphenol penta ethoxylates (NPPE) and octylphenol penta ethoxylates (OPPE) were of technical grade; the remaining both APEs and PBBs were of analytical grade. The polybrominated diphenyl ethers (PBDEs) mixtures were purchased from AccuStandard, USA, and were of analytical grade. TBBPA of technical grade as Firemaster BP4A, and hexabromocyclododecane (HBCD) of technical grade were purchased from AccuStandard, USA. Helium, as He 5.5 pure, was purchased from Air Products South Africa, Vereeniging.

\section{Gas chromatography mass spectrometry (GC-MS) analysis}

An Agilent 6890 gas chromatograph equipped with a 5975 mass selective detector (MSD) was used for GCMS analysis. The MS was tuned with perfluorotributylamine (PFTBA) using the auto-tune program. The GC was equipped with an Agilent autosampler. The GC separation was performed on a capillary column (Restek RTx-1614, film thickness $0.10 \mu \mathrm{m}, 15$ $\mathrm{m} \times 0.25 \mathrm{~mm}$ I.D., (Chromspec cc South Africa). The GC-MS conditions used for analysis were as follows: carrier gas $\mathrm{He}$; linear velocity, $40 \mathrm{~cm} / \mathrm{s}$; injector temperature, $280^{\circ} \mathrm{C}$; transfer line temperature, $300^{\circ} \mathrm{C}$; ion source $150^{\circ} \mathrm{C}$. For the analysis, $1 \mu \ell$ splitless injection was carried out by autosampler. The GC temperature program conditions were as follows: initial temperature $50^{\circ} \mathrm{C}$, heated to $120^{\circ} \mathrm{C}$ by a temperature ramp of $7.5^{\circ} \mathrm{C} / \mathrm{min}$, then $275^{\circ} \mathrm{C}$ by a temperature ramp of $15^{\circ} \mathrm{C} / \mathrm{min}$, then finally heated to $300^{\circ} \mathrm{C}$ (held for $2 \mathrm{~min}$ ) by a temperature ramp of $25^{\circ} \mathrm{C} / \mathrm{min}$.

\section{Derivatization}

The following were added into a pyrex test tube: $80 \mu \ell$ of

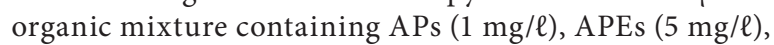
PBBs $(1 \mathrm{mg} / \ell)$, PBDEs ( $1 \mathrm{mg} / \ell)$, HBCD (5 mg/ $\ell$ ), TBBPA (5 $\mathrm{mg} / \ell$ ), $0.1 \mathrm{~m} \ell$ hexane; $70 \mu \ell$ of $0.1 \mathrm{M}$ triethylamine (TEA) and $7 \mu \ell$ HFBA. The test tubes were closed and completely mixed for 1 min using a vortex system. The contents were gradually heated to $50^{\circ} \mathrm{C}$ and the derivatization monitored by GC-MS. Derivatization was achieved within $30 \mathrm{~min}$.
Thereafter, the contents were cooled, quenched with $0.3 \mathrm{ml}$ of $5 \%$ aqueous solution of $\mathrm{K}_{2} \mathrm{CO}_{3}$. The organic phase was then drawn off. The aqueous phase was washed twice with $0.5 \mathrm{~m} \ell$ hexane to recover some organic fractions. After separation, the organic phase extracts were concentrated to 100 $\mu \ell$. Thereafter, the internal standards (Chrysene and PBB80) were added into the extract, the volume made up to $200 \mu \ell$ and $1 \mu \ell$ of a mixture of extracts and internal standards injected into the GC-MS.

\section{Extraction of analytes from simulated water samples}

Solid-phase extraction (SPE) was used as the isolation technique throughout the experiment. Before use, the SPE cartridge was conditioned with $6 \mathrm{ml}$ of $30 \% \mathrm{MeOH}$ in dichloromethane (DCM) followed by the addition of $6 \mathrm{~m} \ell$ of $\mathrm{MeOH}$. About 250 $\mathrm{m} \ell$ of MilliQ water, spiked with $80 \mu \ell$ of organic mixture, was acidified to $\mathrm{pH} 3$ with acetic acid and extracted at a flow rate of approximately $10 \mathrm{ml} / \mathrm{min}$. After passing the sample, the cartridge was dried under vacuum for $1 \mathrm{~h}$. The compounds were eluted with $3 \times 2 \mathrm{ml}$ of mixture of DCM-hexane. The eluates were evaporated to dryness under a gentle stream of nitrogen at $40^{\circ} \mathrm{C}$. Finally the dried residues were subjected to derivatization reaction as described earlier.

\section{RESULTS AND DISCUSSION}

\section{Derivatization}

HFBA was chosen for the present study because of its rapid and quantitative reaction, the formation of stable products, excellent chromatographic properties for the targeted analytes, as well as the availability of the reagent. The derivatization reaction was monitored by GC-MS using TBBPA as shown in Fig. 1.

Both APEs and TBBPA were fully derivatized with HFBA aided by TEA in the presence of PBBs, PBDEs and HBCD. Under the scope of the derivatization, it was observed that there was no de-bromination of PBBs, PBDEs and HBCD. The GC-MS chromatogram, shown in Fig. 2, indicates that only the hydroxyl groups reacted and this was later used to determine the selected ion monitoring of the target compounds. It was also observed that derivatization depended on the analyte structure, time and solvent. In this study, the derivatization reaction for the phenolic hydroxyl group was completed faster than those for the alcoholic hydroxyl groups. This phenomenon has been reported previously (Hoai et al., 2003).

\section{Recovery of targeted analytes from simulated water samples}

The recovery results from simulated water samples, as shown in Fig. 3, ranged from 60 to $140 \%$. These results were comparable with those reported by other researchers (Cathum and Sabik, 2001; Cai et al., 2003; Hoai et al., 2003; Gatidou et al., 2007; Dirtu et al., 2008). The obtained recovery results were considered to be satisfactory, considering that different types of analytes with different chemical structure and polarities were extracted simultaneously. 

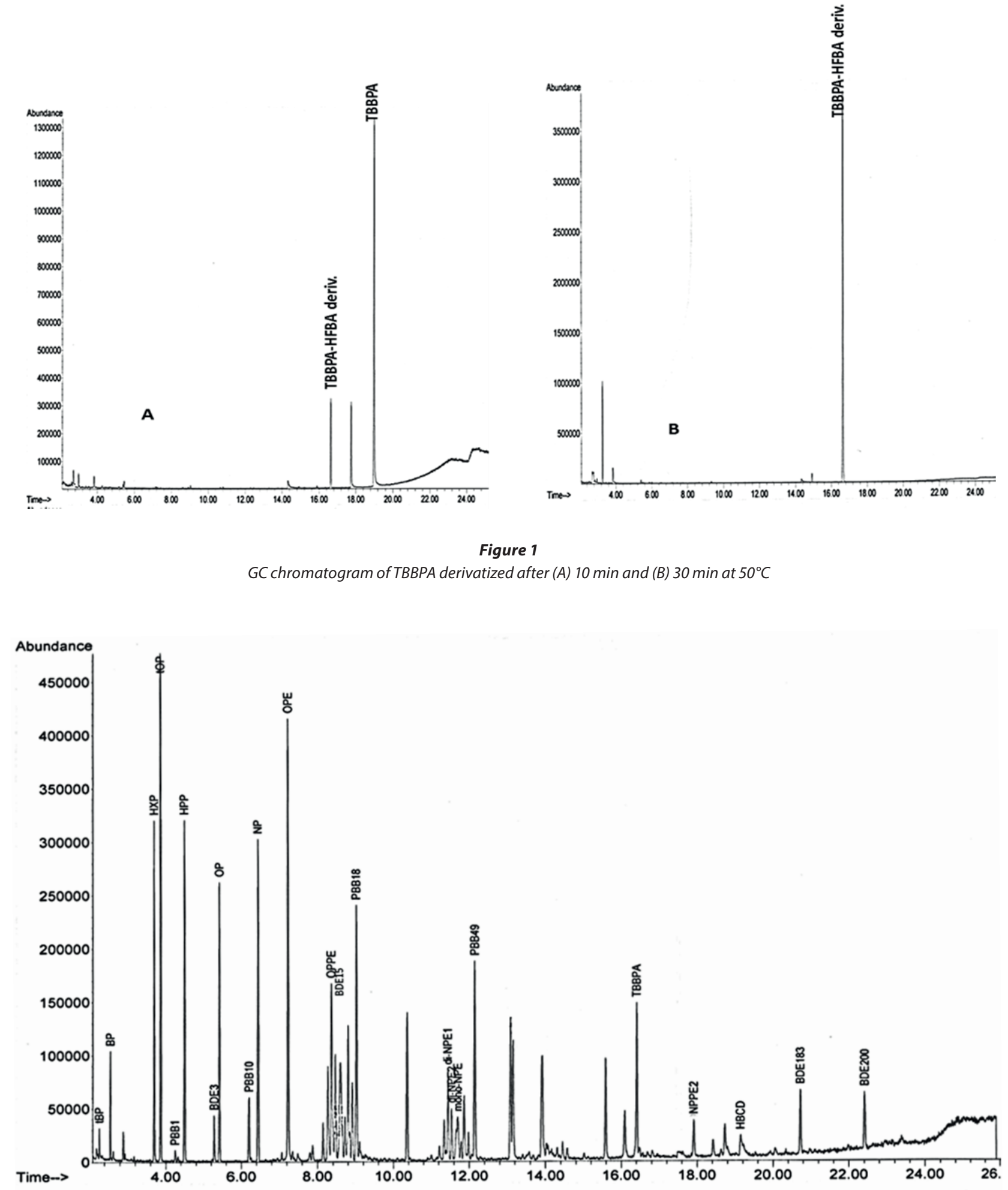

Figure 2

$G C$ chromatogram of derivatized APEs and TBBPA in the presence of PBBS, PBDEs and HBCD standard 


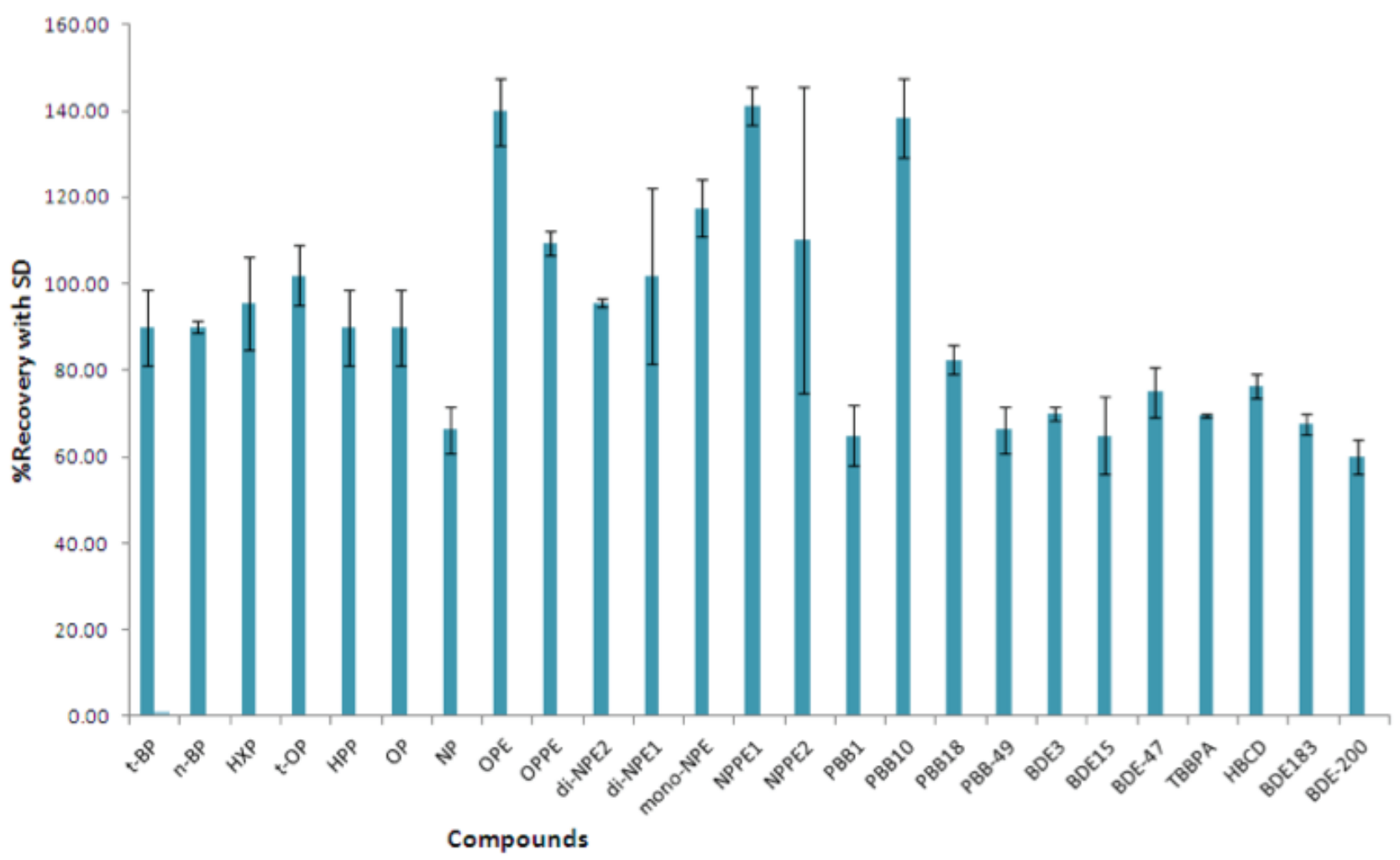

Figure 3

Mean recovery efficiencies of targeted compounds under optimum conditions. Error bars indicate standard deviation

\section{Comparison of the derivatization protocol with other reported studies}

A comparison of the derivatization procedure from this study and previously reported procedures is presented in Table 1. From the results in Table 1, BSTFA yielded a fast derivatization reaction as the reaction was complete within $20 \mathrm{~min}$, but this was obtained at a higher temperature $\left(65^{\circ} \mathrm{C}\right)$ (Gatidou et al., 2007). Another study by Fiedler et al. (2007) also used BSTFA but the reaction took place at room temperature for $2 \mathrm{~h}$. These 2 studies indicated the effect of temperature on derivatization with BSTFA as the derivatization was quicker at an elevated temperature than at room temperature. Hoai et al. (2003) obtained quicker derivatization products at room temperature with BSA than with BSTFA as the derivatized products were obtained in $1 \mathrm{~h}$. In terms of the speed of derivatization, this study showed a quicker derivatization reaction, except for the studies done by Gatidou et al. (2007). With acylation reagents, this study showed similar reaction times compared to the studies where anhydride derivatizing agents were used (Stehmann and Schröder, 2004; Dirtu et al., 2008). Compared to the conditions reported in Table 1, the derivatization method developed in this study was found to save analysis time as the derivatization was complete within $30 \mathrm{~min}$ under very mild conditions, producing comparable limit of detection (LOD) and limit of quantification (LOQ) results.

\begin{tabular}{|c|c|c|c|c|c|}
\hline \multicolumn{6}{|c|}{$\begin{array}{l}\text { TABLE } 1 \\
\text { Summary of derivatization procedures in water samples in the literature }\end{array}$} \\
\hline Compounds & Derivatizing agent & Conditions & $\operatorname{LOD}(\mu \mathrm{g} / \ell)$ & LOQ $(\mu \mathrm{g} / \ell)$ & Ref. \\
\hline NPEO & $\begin{array}{l}n \text {-propanol-acetyl- } \\
\text { chloride }\end{array}$ & $80^{\circ} \mathrm{C}, 1 \mathrm{~h}$ & NR & 0.01 & Ding and Tzing, 1998 \\
\hline APnEO & $\mathrm{PFB}-\mathrm{Br}+\mathrm{K}_{2} \mathrm{CO}_{3}$ & $\begin{array}{l}2 \mathrm{~h} \text { ultrasonic bath then } \\
\text { overnight in dark place }\end{array}$ & $0.001-0.002$ & NR & $\begin{array}{l}\text { Cathum and Sabik, } \\
2001\end{array}$ \\
\hline NPnEOs, NPnECs & BSA & $25^{\circ} \mathrm{C}, 1 \mathrm{~h}$ & $0.0025-0.018$ & NR & Hoai et al., 2003 \\
\hline NP, BPA & TFAA & $60^{\circ} \mathrm{C}, 30 \mathrm{~min}$ & NR & NR & $\begin{array}{l}\text { Stehmann and } \\
\text { Schröder, } 2004\end{array}$ \\
\hline NPnEO & BSTFA and TMCS & $70^{\circ} \mathrm{C}, 4 \mathrm{~h}$ & NR & NR & Esperanza et al., 2004 \\
\hline NP, NP2EO, BPA, TCS & BSTFA & $65^{\circ} \mathrm{C}, 20 \mathrm{~min}$ & $0.03-0.41$ & $0.11-1.34$ & Gatidou et al., 2007 \\
\hline AP & BSTFA & room temperature, $2 \mathrm{~h}$ & NR & NR & Fiedler et al., 2007 \\
\hline BPA, TCS, TBBPA & PFPA + TEA & $70^{\circ} \mathrm{C}, 30 \mathrm{~min}$ & $0.02-0.04$ & $0.05-0.280$ & Dirtu et al., 2008 \\
\hline APs, APEs, TBBPA & $\mathrm{HFBA}+\mathrm{Na}_{2} \mathrm{CO}_{3}$ & $55^{\circ} \mathrm{C}, 2 \mathrm{~h}$ & $0.01-0.15$ & $0.05-0.66$ & Chokwe et al., 2012 \\
\hline APs, APEs, TBBPA & HFBA + TEA & $50^{\circ} \mathrm{C}, 30 \mathrm{~min}$ & $0.01-0.15$ & $0.05-0.66$ & This study \\
\hline
\end{tabular}

$\mathrm{NR}=$ not reported $\mathrm{LOD}=$ limit of detection; $\mathrm{LOQ}=$ limit of quantification 


\section{CONCLUSIONS}

The derivatization method presented here for the simultaneous determination of APEs and TBBPA gave comparable results with other derivatization studies in the literature. The derivatization procedure in this study involved the reaction of these compounds simultaneously in the presence of lower congeners of PBBs, PBDEs and HBCD, with HFBA under triethylamine base at $50^{\circ} \mathrm{C}$ for $30 \mathrm{~min}$. The results of this study demonstrate that the presented method has acceptable relative recoveries of $60 \pm 3.86-141 \pm 4.24$ for the target compounds and adequate LOD and LOQ that ranged from $0.01-0.20 \mu \mathrm{g} / \ell$ and $0.05-0.66 \mu \mathrm{g} / \ell$, respectively. The presented method showed milder derivatization conditions and shorter analysis time.

\section{ACKNOWLEDGEMENTS}

The authors are indebted to Rand Water for providing the technical environment and funding for this project, which is part of Mr Chokwe's doctoral degree, and to Tshwane University of Technology for support.

\section{REFERENCES}

ALAEE M, SERGEANT DB, IKONOMOU MG and LUROSS JM (2001) A gas chromatography/high resolution mass spectrometry (GC/ HRMS) method for determination of polybrominated diphenyl ethers in fish. Chemosphere 44 1489-1495.

CAI Y, JIANG G, LIU J and ZHOU Q (2003) Multiwalled carbon nanotubes as a solid-phase extraction adsorbent for the determination of bisphenol A, 4-n-nonylphenol and 4-tert-octylphenol. Anal. Chem. 75 2517-2521.

CATHUM S and SABIK H (2001) Simultaneous determination of alkylphenol polyethoxylate surfactants and their degradation products in water, effluent and mussel using gas chromatography-mass spectrometry. Chromatographia Supplement 53 400-405.

CHOKWE TB, OKONKWO JO, SIBALI LL and NCUBE EJ (2012) Optimization and simultaneous determination of alkylphenol ethoxylates and brominated flame retardants in water after SPE and heptafluorobutyric anhydride derivatization followed by GC/MS. Chromatographia 75 1165-1176.

DING WH and TZING SH (1998) Analysis of nonylphenol polyethoxylates and their degradation products in river water and sewage effluent by gas chromatography-ion trap (tandem) mass spectrometry with electron impact and chemical ionization. J. Chromatogr. A 824 79-90.

DIRTU AC, ROOSENS L, GEENS T, GHEORGHE A, NEELS H and COVACI A (2008) Simultaneous determination of bisphenol A, triclosan and tetrabromobisphenol $\mathrm{A}$ in human serum using solid-phase extraction and gas chromatography-electron capture negative ionization mass spectrometry. Anal Bioanal. Chem. 391 $1175-1181$.

ESPERANZA M, SUIDAN MT, NISHIMURA F, WANG ZM, SORIAL GA, ZAFFIRO A, MCCAULEY P, BRENNER R and SAYLES G
(2004) Determination of sex hormones and nonylphenol ethoxylates in the aqueous matrixes of two pilot scale municipal wastewater treatment plants. Environ. Sci. Technol. 38 3028-3035.

FIEDLER S, FOERSTER M, GLASER B and ZECH W (2007)

Alkyphenols in sediments of the Atlantic Rainforest south-west of São Paulo, Brazil. Chemosphere 66 212-218.

GATIDOU G, THOMAIDIS NS, STASINAKIS AS and LEKKAS TD (2007) Simultaneous determination of the endocrine disrupting compounds nonylphenol, nonylphenol ethoxylates, triclosan and bisphenol A in wastewater and sewage sludge by gas chromatography-mass spectrometry. J. Chomatogr. A 1138 32-41.

HOAI PM, TSUNOI S, IKE M, KURATANI Y, KUDOU K, VIET PH, FUJITA $M$ and TANAKA M (2003) Simultaneous determination of degradation products of nonylphenol polyethoxylates and their halogenated derivatives by solid-phase extraction and gas chromatography-tandem mass spectrometry after trimethylsilylation. $J$. Chromatogr. A 1020 161-171.

HYÖTYLÄINEN T and HARTONEN K (2002) Determination of brominated flame retardants in environmental samples. Trends Anal. Chem. 21 13-29.

ODUSANYA DO, OKONKWO JO and BOTHA B (2009) Polybrominated diphenyl ethers (PBDEs) in leachates from selected landfill sites in South Africa. Waste Manage. 29 96-102.

OLUKUNLE O, OKONKWO J, KEFENI K and LUPANKWA M (2012) Concentrations of polybrominated diphenyl ethers in sediments from Jukskei River, Gauteng, South Africa. Bull. Environ. Contam. Toxicol. 88 461-466.

PETROVIC M, BARCELÓ D, DIAZ A and VENTURA F (2003) Low nanogram per liter determination of halogenated nonylphenol, nonylphenol carboxylates and their non-halogenated precursors in water and sludge by liquid chromatography-electrospray-tandem mass spectrometry. J. Am. Soc. Mass Spectrom. 14 516-527.

POLDER A, BESTER B, SKAARE JU and BOUMAN H (2008) Polybrominated diphenyl ethers (PBDEs) in bird eggs from South Africa. Chemosphere 73 (2) 148-154.

SEGEV O, KUSHMARO A and BRENNER A (2009) Environmental impact of flame retardants (persistence and biodegradability). Int. J. Environ. Res. Public Health 6 (2) 478-491.

SIBALI LL, OKONKWO JO and MCCRINDLE RI (2010) Levels of selected alkylphenol ethoxylates (APEs) in water and sediment samples from Jukskei River catchment area in Gauteng, South Africa. Water SA 36 (3) 229-238.

STEHMANN A and SCHRÖDER HF (2004) Derivatization of 4-nonylphenol and bisphenol A with halogenated anhydrides. Water Sci. Technol. 50 (5) 115-118.

VETTER W, VON DER RECKE R, SYMONS R and PYECROFT S (2008) Determination of polybrominated biphenyls in Tasmanian devil (Sarcophilus harrisii) by gas chromatography coupled to electron capture ion tandem mass spectrometry or electron ionization high-resolution mass spectrometry Rapid Commun. Mass Spectrom. 22 4165-4170.

YING GG, WILLIAMS B and KOOKANA R (2002) Environmental fate of alkylphenols and alkylphenol ethoxylates - a review. Environ. Int. 28 215-226.

YU Z, PENG P, SHENG G and FU J (2008) Determination of hexabromocyclododecane diastereoisomers in air and soil by liquid chromatography-electrospray tandem mass spectrometry. J. Chromatogr. A 1190 74-79. 